\title{
Focusing on Data: Year 5 Students Making STEM Connections
}

\author{
Noleine Fitzallen ${ }^{1}$, Suzie Wright, Jane Watson \\ University of Tasmania, Australia
}

\begin{abstract}
Integrated STEM learning experiences provide the opportunity for students to make connections among the various disciplines. The outcomes for many STEM activities, however, are only reported for one discipline and provide little guidance for taking an integrated approach to learning in the classroom. This paper reports on a Year 5 STEM activity based on designing, making, and trialling seed dispersal devices. A focus on the data collected by the class and the subsequent graphical representations created during followup interviews, illustrates the way in which the students made connections to multiple STEM disciplines. The results indicate that Year 5 students have the capacity to use graphical representations of data to describe the performance of seed dispersal devices and base informal inferences about the performance of the devices on their knowledge of design, construction, materials, and flight from the various STEM disciplines.
\end{abstract}

Keywords: STEM education, Graphical representations; Variation; Practice of Statistics

STEM (Science, Technology, Engineering and Mathematics) learning experiences that take an integrated curriculum approach provide students with the opportunity not only to learn content but also to apply that knowledge within meaningful real-life related contexts. Unfortunately, implementation of such activities has resulted in little change in pedagogical practices and has not given rise to new ways of conceptualising the Australian Curriculum (Blackley \& Howell, 2015). Blackley and Howell, and others (e.g., Fitzallen, 2015), lament the lack of evidence-based guidance for teachers to implement change and the pressure placed on teachers to deliver STEM learning outcomes within a curriculum with discrete subjects for each discipline. Compounding the issue is that the Australian Curriculum does not include Engineering as a subject (Australian Curriculum, Assessment and Reporting Authority [ACARA], 2019). The recent release of the Australian Curriculum: Design and Technologies has gone some way to alleviating the issue by including engineering-related practices such as designing, creating, modelling, critiquing and evaluating. Although the Design and Technologies curriculum states that students will create designed solutions for the technological context of "Engineering principles and systems", the content descriptors do not refer explicitly to engineering. The subtle way in which engineering principles and systems are included in the Design and Technologies curriculum does not give the discipline of engineering the same standing in the Australian Curriculum as the other disciplines included in the STEM acronym.

STEM integration is often reported in relation to the number of disciplines addressed purposefully in a learning activity (e.g., Becker \& Park, 2011; Fraser, Earle, \& Fitzallen, 2019). With a focus on engineering, Moore and Smith (2014), however, offer two different ways to integrate

\footnotetext{
${ }^{1}$ Corresponding Author: Noleine Fitzallen, School of Education | College of Arts, Law and Education, University of Tasmania, Room 504, Hytten Hall, Sandy Bay, Private Bag 66, Hobart TAS $7001+6136226$ 2524. Contact: noleine.fitzallen@utas.edu.au

Fitzallen, N., Wright, S., \& Watson, J. (2019). Focusing on data: Year 5 students making STEM connections. Journal of Research in STEM Education, 5(1),
} $1-19$ 
curriculum content with engineering design principles: Context integration and Content integration. Context integration refers to using the engineering design process to help students learn the subject knowledge from the other STEM disciplines, primarily mathematics and science. In these instances, the engineering design process is the main learning focus and is used as a step-by-step model to structure learning. This also includes taking advantage of the cyclical nature of the process when designed solutions are reviewed and modified (e.g., English, Hudson, \& Dawes, 2013; Ward, Lyden, \& Fitzallen, 2016). Unfortunately, research that reports outcomes from taking a context integration approach often only reports on the outcomes of implementing the engineering design process and rarely reports on the outcomes associated with the subject content knowledge encompassed in learning activities.

Content integration refers to the integration of engineering thinking and subject knowledge where the focus is on delivering engineering content and STEM discipline knowledge as learning goals (Moore, Guzey, \& Brown, 2014). Again, research that takes this approach mostly reports on the engineering outcomes (e.g., English et al., 2013; Ward et al., 2016) and rarely includes the potential outcomes for the other STEM disciplines encompassed in the learning activities. The dichotomy set up between the two integration models proposed by Moore and Smith (2014) does little to support teachers wanting to take an holistic integrated STEM approach in the classroom. An amalgamation of context and content integration seems desirable but research on the implications of such an approach is sparse.

In recent times, more holistic conceptual models of STEM have emerged from the literature (e.g., Kelley \& Knowles, 2016; Lowrie, Leonard, \& Fitzgerald, 2018). The conceptual model proposed by Kelley and Knowles is a five-part model that includes the way in which people learn and work within the four STEM disciplines: engineering design, scientific inquiry, technological literacy, and mathematical thinking. The model also includes a Community of Practice (Lave \& Wenger, 1991) as the element that facilitates integration. Kelley and Knowles go further to propose that the engineering design process provides the context and the platform for STEM learning. The emphasis on the engineering design process and the addition of the community of practice in the Kelley and Knowles conceptual model of STEM increases the complexity of the notion of STEM and may limit its applicability. As it stands, the conceptual model does not account for STEM learning that is not embedded within engineering design contexts. Also, including the community of practice element is problematic. A community of practice in the school context relies on community experts (e.g., practicing engineers) to mentor novice learners. The opportunity to invite experts into classrooms and for them to engage with learners as they work through design projects for a sustained period is not always possible due to the uncertain proximity and availability of experts, and the time demands such an approach places on teachers and experts alike.

The conceptual model developed by Lowrie and his colleagues (2018) presents a broader model than the one developed by Kelley and Knowles (2016). Like Kelley and Knowles, Lowrie and his colleagues developed a model that does not address STEM discipline content specifically. It is a heuristic based on a pedagogical approach related to the early years of schooling (K-Year 2): Experience, Represent, Application. This model emphasises the importance of giving students the opportunity to have hands-on experiences that build on their prior learning and extend their understanding beyond the immediate context of the new learning, which is relevant to all levels of schooling. Although a simple model to enact in the classroom, the lack of acknowledgement of the way in which students learn in the various STEM disciplines in the model may result in learning experiences being driven by subject content knowledge, thereby, potentially limiting the heuristic as a way of promoting integrated STEM learning. 
The recent emergence of the models of Kelley and Knowles (2016) and Lowrie and colleagues (2018) positions these new ideas from the literature as theoretical frameworks and would benefit from research to validate and refine them. More research that reports findings about STEM learning holistically using integrated STEM learning models, from an inter-connected perspective, is needed. This would provide evidence-based practical applications, programs or interventions to address integrated STEM learning (Honey, Pearson, \& Schweingruber, 2014; Rosicka, 2016) and allay concerns that developing subject content knowledge is secondary to improving student engagement and motivation in the primary classroom (Fitzallen, 2015; Shaughnessy, 2013). This paper aims to add to the discourse about what constitutes integrated STEM learning. It seeks to illustrate the way in which students make connections to the STEM disciplines when the context integration is focused on the engineering design process and the content integration is focused on mathematics learning outcomes. The research question addressed is, "What connections do students make to the various STEM disciplines when conducting an investigation that is framed by the engineering design process and focused on developing outcomes in data and statistics?"

\section{Research Background}

The research reported in this paper draws on two conceptual frameworks - the Engineering Design Process (Kelley \& Knowles, 2016) and the Practice of Statistics (Moore \& McCabe, 1989; Watson, Fitzallen, Fielding-Wells, \& Madden, 2018). The engineering design process underpins the integrated STEM framework proposed by Kelley and Knowles. It includes:

1. Identify problem - the engineer must be fully aware of what the problem entails and how this may affect people.

2. Brainstorm solutions - the engineer thinks of any ideas (both possible and improbable) that may lead to a suitable solution to the identified problem.

3. Design - the engineer will select one of the most suitable ideas developed in the brainstorm phase and start to create a full design for this idea.

4. Build - the engineer will build a prototype of the design.

5. Test and evaluate - the engineer will test the prototype under suitable conditions and assess its performance based on the established understanding of the problem.

6. Redesign - the engineer will identify features for improvement, which are redesigned and modified. (Ward et al., 2016, p. 11).

In the engineering design process there is an explicit understanding that modified devices or models would undergo retesting and re-evaluation. Although useful for framing learning experiences, Kelley and Knowles acknowledge that the engineering design process is limited because it does not account for STEM learning that is not embedded within engineering design learning experiences.

The practice of statistics was chosen as a conceptual model to underpin the mathematics content covered by the activity implemented in the classroom. The practice was first conceptualised by Moore and McCabe (1989) as a way of initiating curriculum reform in higher education statistics courses. Watson and colleagues (2018) extended these ideas by demonstrating the way in which the practice of statistics applies to the compulsory years of schooling. The practice of statistics is based on the way in which statisticians work and the premise that "statistical problem solving and decision making depend on understanding, explaining, and quantifying the variability in the data" (Franklin et al., 2007, p. 6) throughout an investigation. The steps in statistical problem solving outlined in the Guidelines for Assessment and Instruction in Statistics Education (GAISE) Report (Franklin et al.) are: 
i. Formulate Questions,

ii. Collect Data,

iii. Analyse Data, and

iv. Interpret Results.

Like the engineering design process, the practice of statistics facilitates a cyclical review of results and promotes collecting more data to measure improvement, confirm results, or make comparisons. Similarly, the practice of statistics is not relevant or applicable when the way in which real-life situations are examined does not require data.

Individually, the engineering design process and the practice of statistics are limited in reach as integrated STEM learning models but do share similarities. The engineering design process provides students with a systematic approach to solving problems based on designing, constructing, and testing the performance of design solutions (Kelley \& Knowles, 2016). The practice of statistics also facilitates a problem-solving approach but focuses on the collection of data to make evidencebased decisions (Watson et al., 2018). It seems logical that considering the two frameworks in tandem may enrich students' STEM learning experiences.

The alignment of the engineering design process and the practice of statistics is illustrated in Figure 1. Although organised in Figure 1 as two separate entities, the enactment of integrating the two processes within a STEM investigation potentially results in an amalgamation of student actions and ideas from the two processes. It is likely one process will have a greater focus than the other at various times during an investigation and that focus would shift to the other process depending on the stage of the investigation. For example, the focus would be on the engineering design process when first designing a prototype and the focus would be on the practice of statistics when collecting and analysing data to measure the performance of the prototype. Later, the engineering design process and the practice of statistics work in tandem when decisions about the modifications to be made are based on the results from the data analysis. 


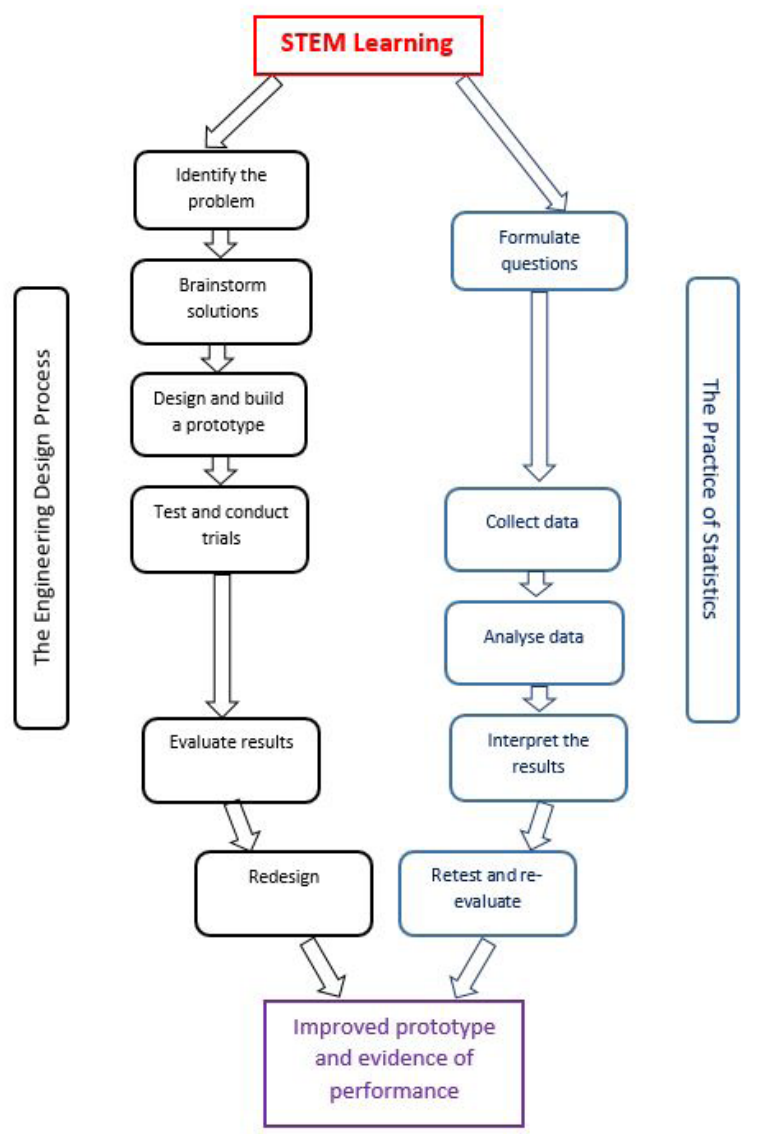

Figure 1: The alignment of the Engineering Design Process and the Practice of Statistics in STEM learning.

For the sake of simplicity, the two models are displayed in Figure 1 in chronological order of implementation during a learning experience, if entry to a project begins with identifying a problem (engineering design process) or posing a question (practice of statistics). This linear representation distorts the dynamic nature of an investigation and the capacity of both frameworks to initiate student engagement at any stage of either framework. In relation to the implementation of the practice of statistics, for example, Watson et al. (2018) illustrate the way in which students compared the difference in manufacturing licorice by hand or machine when the question posed, and the method of data collection were already established by the teacher. Similarly, entry into the engineering design process could occur when students are given a device and asked to improve its performance, even though they may not have been involved in the original design and construction of the device.

According to the Increasing Levels of Integration continuum described by Vasquez (2015), the integration of the engineering design process with the practice of statistics would be considered multidisciplinary integration. At the multidisciplinary level of integration, "Students learn concepts and skills from two or more disciplines that are tightly linked so as to deepen knowledge and skills" (p. 13). Learning experiences at this level of integration go beyond learning about concepts and ideas through a thematic approach in separate subject areas, which is characteristic of multidisciplinary integration. The level of integration for this study does not extend to transdisciplinary integration because the investigation that the students conducted was largely teacher-directed and contained within the one learning activity. 


\section{Research Approach}

This research draws on qualitative research methods and techniques (Creswell, 2014; Johnson \& Onwuegbuzie, 2004) to explore the way in which students make connections among the STEM disciplines from the creating and trialling of an engineered device. Evidence of the connections made were collected via student interviews.

A semi-structured interview schedule was developed to guide the interviewers. Semi-structured interviews provide a depth of data that is difficult to gather by other means (Fontana \& Frey, 2003). They provide the opportunity for ideas expressed to be clarified and expanded. In this way rich, descriptive data are collected (Cobb, Confrey, diSessa, Lehrer, \& Schauble, 2003). Silverman (2003) warns, however, that although qualitative data collection methods, such as interview, provide valuable information about "how people see things," the methods often ignore the importance of "how people do things" (p. 359). This concern was addressed in this study by conducting the interviews while students used the educational data analysis software, TinkerPlots (Konold \& Miller, 2015), to create data representations and analyse the data collected from the design activity.

To draw out students' understanding of data and statistics, and more specifically variation within the STEM context, as evidenced in graphical representations, the interview questions were based on the four categories of Shaughnessy's (2007) student understanding of graphs framework:

- Read the data: Recognising components of graphs.

- Read within the data: Understanding relationships among elements of graphs and the data.

- Read beyond the data: Interpreting information in the graph.

- Read behind the data: Looking for possible causes and implications of variation in the data.

The first three categories of Shaughnessy's framework were proposed by Curcio (2001), who considered school students' interpretation of graphs from the three perspectives. The additional category proposed by Shaughnessy, Read behind the data, gave the Curcio model greater depth in terms of the way students develop graph sense. It also attended to the importance of using data for a purpose, for example, to make decisions and informal inferences (Makar \& Rubin, 2009).

The reason for focusing on the students' understanding of graphs was to identify the connections the students made from the mathematical content associated with data and statistics covered by the investigation to the ideas and concepts related to the other STEM disciplines. The assumption was made that a discussion about the data collected within a meaningful STEM context would prompt the students to think more broadly about that context. As Rao (1975) posits, statistics require data and data require context. The decision not to ask direct questions about the connections the students made to the STEM disciplines in the interview was to alleviate the issues associated with asking leading questions (Kvale, 1996). The aim was to let the connections the students made emerge from the interviews, which is in keeping with the exploratory nature of the study (Creswell, 2014).

\section{The Study}

The activity that was the setting for the study reported here was the seventh implemented for one of the schools in the longitudinal project, Modelling with Data: Advancing STEM in the Primary Curriculum, which followed students from the middle of Year 3 to the end of Year 6. The activity reported here took place near the end of Year 5. The aim of the overall project was to build on the potential of the practice of statistics to enhance STEM learning as the students developed understanding of working with data, which is the basis of the practice of statistics (Watson et al., 
2018). The STEM activities provided the contexts within which data were collected, analysed, and interpreted. Indeed, as Rao suggested in 1975, "Statistics should not be taught as a separate discipline, as the sole purpose is to inculcate in the students quantitative approach and thinking, and this cannot be done without reference to real problems" (p. 161). The project had ethics approval from the Tasmania Social Sciences Human Research Ethics Committee (H0015039).

In Year 3 the first activity focused on the advantage of consistency in a manufacturing process by comparing the variation in the mass of a product made by hand and by machine (Watson, Fitzallen, English, \& Wright, 2019). The second activity expanded the sources of variation by considering the difference in the change in temperature of insulated and non-insulated cups initially filled with hot water and placed in a water bath of cold water, followed by the introduction of ice in the water bath 10 minutes later (Fitzallen, Wright, Watson, \& Duncan, 2016). This activity, focusing on heat, expanded the appreciation of ways to represent data in graphical formats (Fitzallen, Watson, \& Wright, 2017).

At the beginning of Year 4, the focus expanded to include the posing of questions in the practice of statistics, as students posed questions to become acquainted with students and their environment in a sister school in another state (English, Watson, \& Fitzallen, 2017). After collecting the data, using an on-line survey to deliver the questions, they again analysed and interpreted their data (Watson, Fitzallen, \& Wright, 2019). More focus was placed on the engineering design process along with the Science topics of force and energy at the end of Year 4 when students considered the performance of a basic catapult to launch an object and then whether "improvements" meant that the catapult would launch the object further (Fitzallen, Watson, Wright, \& Duncan, 2018). In Year 5, students undertook two activities related to the Science topic of viscosity. First, they collected data on several different densities of a substance to find the concentration of a mystery density, and then simulated lava flow down a model of a "volcano" to determine the time needed to travel a distance beyond the distances for which the data were collected (Fitzallen \& Watson, in press).

By the end of Year 5 it was felt important to focus more on the design-and-build elements of the engineering design process (Figure 1) and to use data to make decisions about design modifications. Hence the decision was made to consider a design problem in a Science topic: the device by which plants disperse their seeds in the wind. This report focuses on the student interviews conducted 8 weeks after the implementation of the classroom activity.

\section{Implementation of the Study}

Fifty-four Year 5 students in two classes at an urban independent Catholic school participated in all stages of the seed dispersal activity. To set the scene for the activity, the classroom discussion focused on sustainability, the need for the conservation of plant species, and the methods plants use to disperse seeds covered by the cross-curriculum priority of Sustainability, outlined in the Australian Curriculum (ACARA, 2019). The activity implemented in the classroom was based on the topic of wind dispersed seeds (adapted from Pike, 2017), which required students to construct a seed dispersal device to carry a seed as far as possible.

Based on the integrated STEM framework that included the engineering design process and the practice of statistics (Figure 1), the Year 5 students enacted the engineering design process when they worked in groups of three to design, create, test, evaluate, modify, and re-test devices to disperse seeds. The groups were assigned one of three types of dispersal devices - sails, parachutes or helicopters - for which each group member built a prototype. The prototypes were constructed from a variety of materials, such as feathers, polystyrene balls, fabric, paper, and wooden sticks. An example of a design drawn, and the prototype constructed (parachute), is shown in Figure 2. A full description of the activity and more examples of devices constructed are reported in Smith, Fitzallen, Watson, and Wright (2019). 


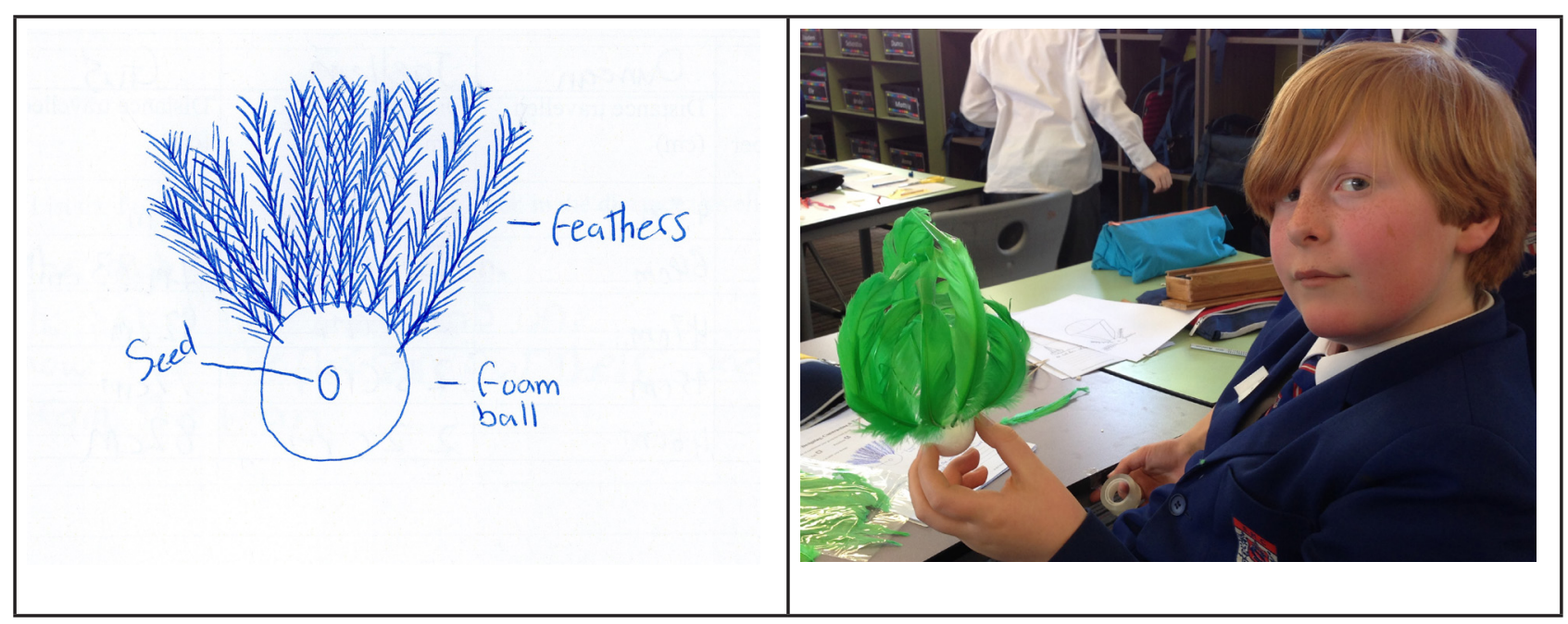

Figure 2. Design and constructed prototype of a seed dispersal device.

The members of each group launched their individual prototypes in front of a free-standing electric fan five times and measured the distance travelled each time (Figure 3). After the data were collected and evaluated, the students used the data and results from the trials to make an informed decision about which prototype was to be modified and re-trialled. The group members then worked together to modify the design and collect more data. They tested the modified design another five times and compared the data to that collected earlier to determine if the modified device dispersed the seed further than before.

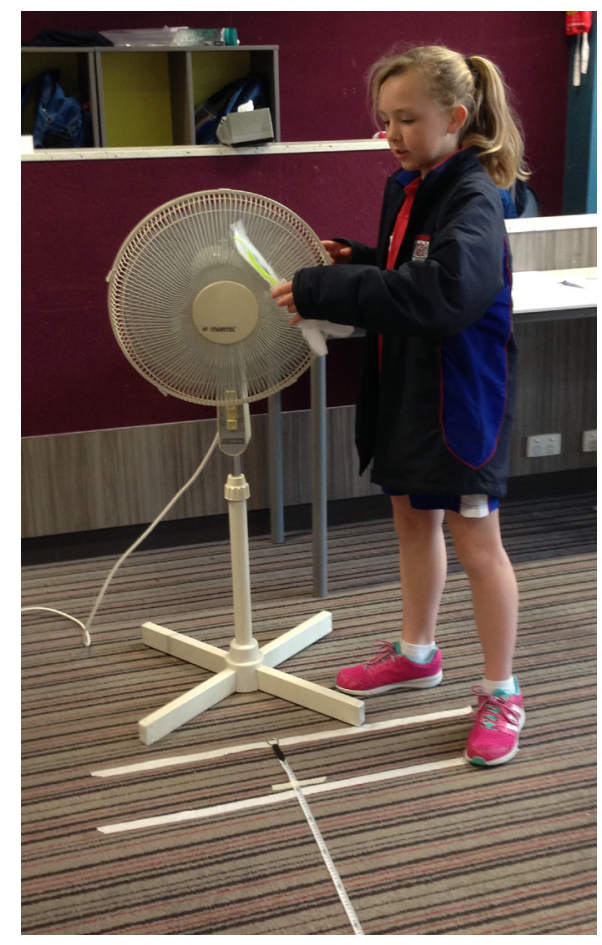

Figure 3. Launching a prototype: Sail.

The data from the trials of the modified devices were entered by the third author in TinkerPlots and used to support class discussion about the distribution of the data for each model and the variation in the distance travelled among the results for the three types of seed dispersal devices (Figure 4). These TinkerPlots files were used two months later in individual student interviews. 


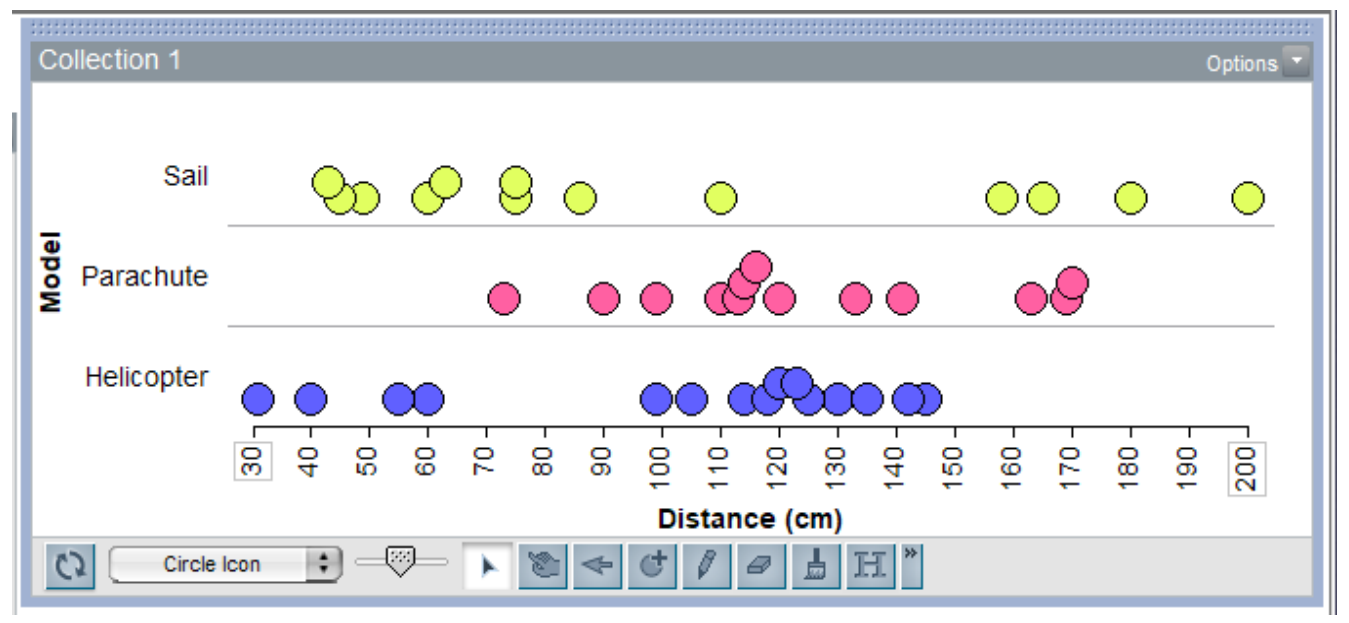

Figure 4. Distribution of data for the three types of seed dispersal devices.

\section{Data Collection: Student Interviews}

Of the 54 students who participated in the learning activity, 45 were interviewed by one of three members of the research team, including authors two and three. The selection of students to interview was based on their availability. No students were excluded for reasons other than their absence at the time of the interviews. The age of the participants at the time of interviewing was 11-12 years, and the gender split was $62 \%$ male and $38 \%$ female.

Each interview lasted approximately 15 minutes. Live screen-capture software was used to record the students' interaction with the TinkerPlots file, and the verbal discussions, which were later transcribed verbatim. Copies of the plots created throughout the interviews were inserted into the transcripts to assist with analysis and interpretation of the students' comments. The data from the interviews were deidentified and are reported using unique codes for each student. For example, [ID789].

The interviews began by asking the students to recall the seed dispersal activity and discuss the processes involved. They were then shown a TinkerPlots file with data collected from their class and told the objective of the interview was to decide if one method of dispersal went the farthest. Initially, the data were arranged randomly on the screen. The students were then encouraged to take control of the TinkerPlots file and manipulate the data display as they deemed appropriate to answer the question. Prompts were given as necessary to assist the students to create a representation that would allow them to make an informed decision (e.g., Figure 4).

The questions asked during the interview were based on Shaughnessy's (2007) student understanding of graphs framework. For example:

* Read the data: Recognising components of graphs

What is the greatest distance travelled by the helicopter seed dispersal device?

* Read within the data: Understanding relationships among the elements of graphs and data Which seed dispersal device was the most consistent and how do you know?

* Read beyond the data: Interpreting information in the graph

What evidence is there in the plot that helps you decide which seed dispersal method went furthest?

* Read behind the data: Looking for possible causes and implications of variation in the data

If you were to design another model, what would you change so that it goes further than the one you made before? 
The semi-structured interview strategy allowed the researchers to ask questions to clarify ideas expressed and probe student thinking, when required.

\section{Data Analysis}

Graphical representations. The representations created in TinkerPlots during the interviews were analysed by the second author. A note was made for each representation to indicate the type created (e.g., split stacked dot plot, continuous scale in bins; random display coloured by attribute, Model; unstacked, split dot plot with the attribute Distance on y-axis, continuous scale), and by whom it was created: the interviewer (i), or the student (s). The code "s (prompted)" was used to indicate when a student required assistance to create the representation.

Student interviews. The interview transcripts were read line by line and codes were assigned to students' responses to the questions asked according to the four categories of Shaughnessy's (2007) student understanding of graphs framework. The second author and an experienced researcher in the field individually coded 11 interviews $(24 \%)$ and then compared their analysis and discussed any discrepancies to come to an agreement. Because the initial level of agreement was $81 \%$ and discrepancies were resolved without conflict, it was decided that second author would continue to code the remaining interviews, with the codes established. The total number of instances for each category were tallied to evidence the relative frequency of each category in the data, and comments within each category were compared qualitatively to determine the types of responses provided by the students. As this was an exploratory study, the aim was to establish the way in which students made connections among the STEM disciplines relevant to the classroom activity rather than determine the level of understanding expressed for the content covered for each of the disciplines.

\section{Results}

\section{Graphical Representations}

Of the 45 students interviewed, one, most likely due to a physical impairment that affects his fine motor coordination, chose not to manipulate the data himself. He was able, however, verbally to direct the interviewer to create a variety of representations and answered all questions without difficulty. The remaining students were all able to manipulate the data and create representations; however, seven required assistance and were prompted to create a suitable final representation to answer the overall question of whether one model went further than the others.

A sample of the final representations created by the 37 students requiring no assistance are shown in Figures 5 and 6. Eighty-nine percent of the students created split dot plots that displayed the attributes Distance and Model (Figures 5a-d). Of these, 11 students (30\%) created a split stacked dot plot with Distance along a continuous scale, coloured either by Model $(n=8)$ or Distance $(n=3)$ (Figure 5a, b); seven students (19\%) created a similar graph without stacking the data (coloured by Model, $n=6$, by Distance, $n=1)$; seven students $(19 \%)$ created a split dot plot with data in bins instead of along a continuous scale (Figure 5c); six students (16\%) created plots with Group and Distance, coloured by Model (5 used continuous scales, and 1 had Distance data sorted in bins); and two students $(5 \%)$ created hat plots, one with vertical reference lines indicating the middle point of each hat, as determined by the student (Figure $5 \mathrm{~d}$ ). Three ( $8 \%$ ) of the remaining four students created single variable plots with Distance on either the horizontal or vertical axis (Figure 6a). The data were coloured by Model but lacked a key to clearly distinguish the three models. Lastly, as his final representation, one student chose to remove data values to leave only the Distance travelled by the Helicopters (Figure 6b). 


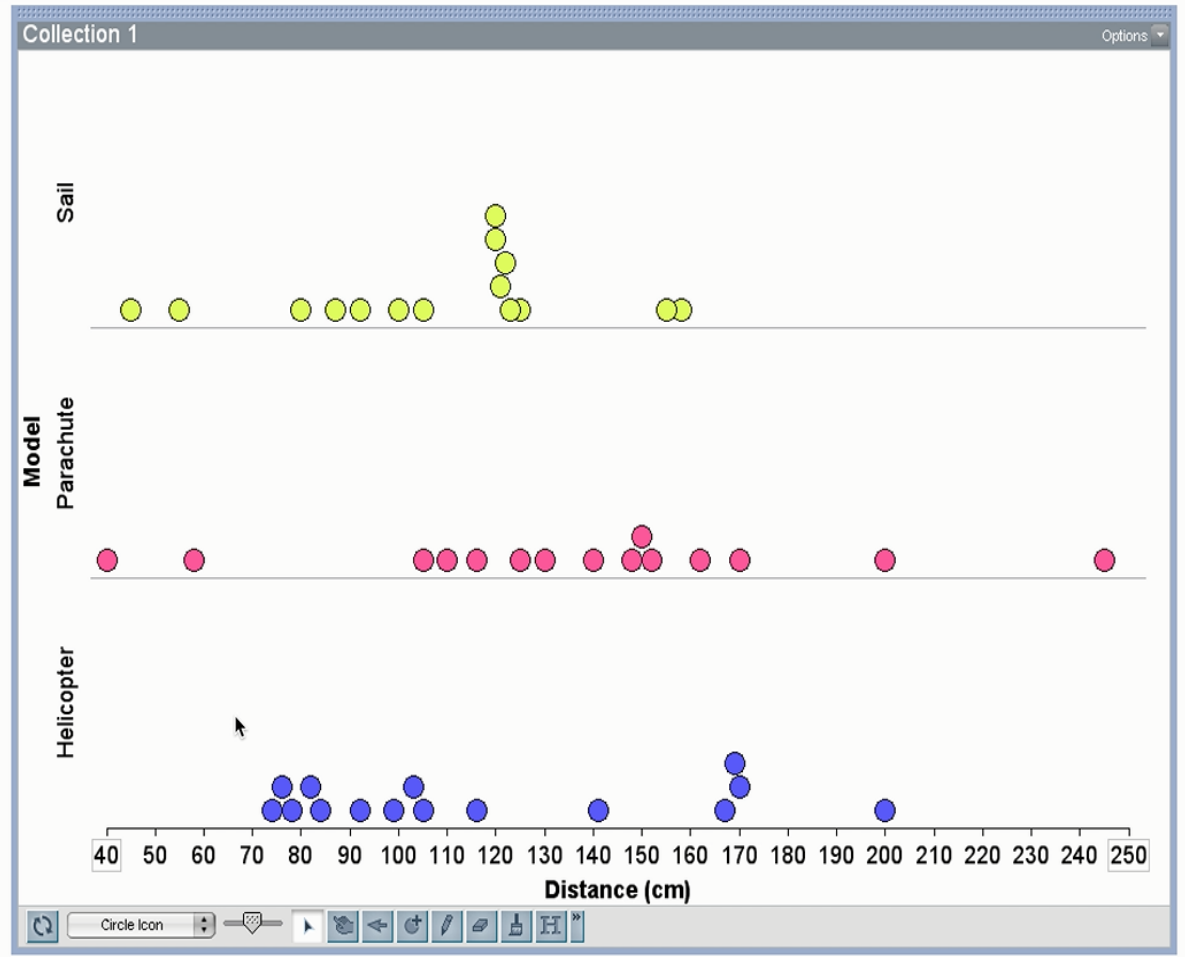

Figure 5a. Split stacked dot plots showing Distance and Model, with continuous scale, coloured by Model (n=8) [e.g., ID159]

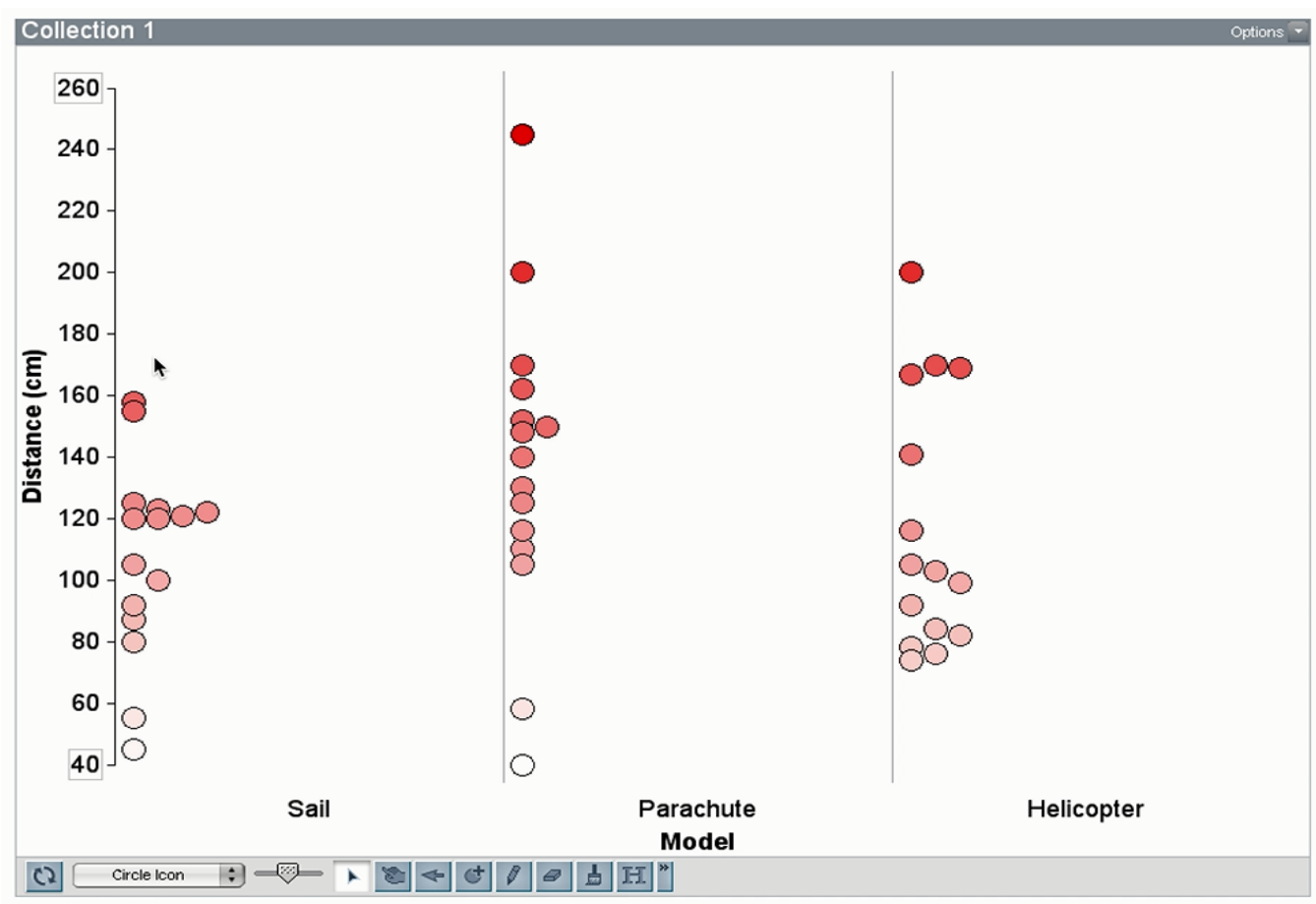

Figure 5b. Split stacked dot plots showing Distance and Model, with continuous scale, coloured by Distance (n=3) [e.g., ID148] 


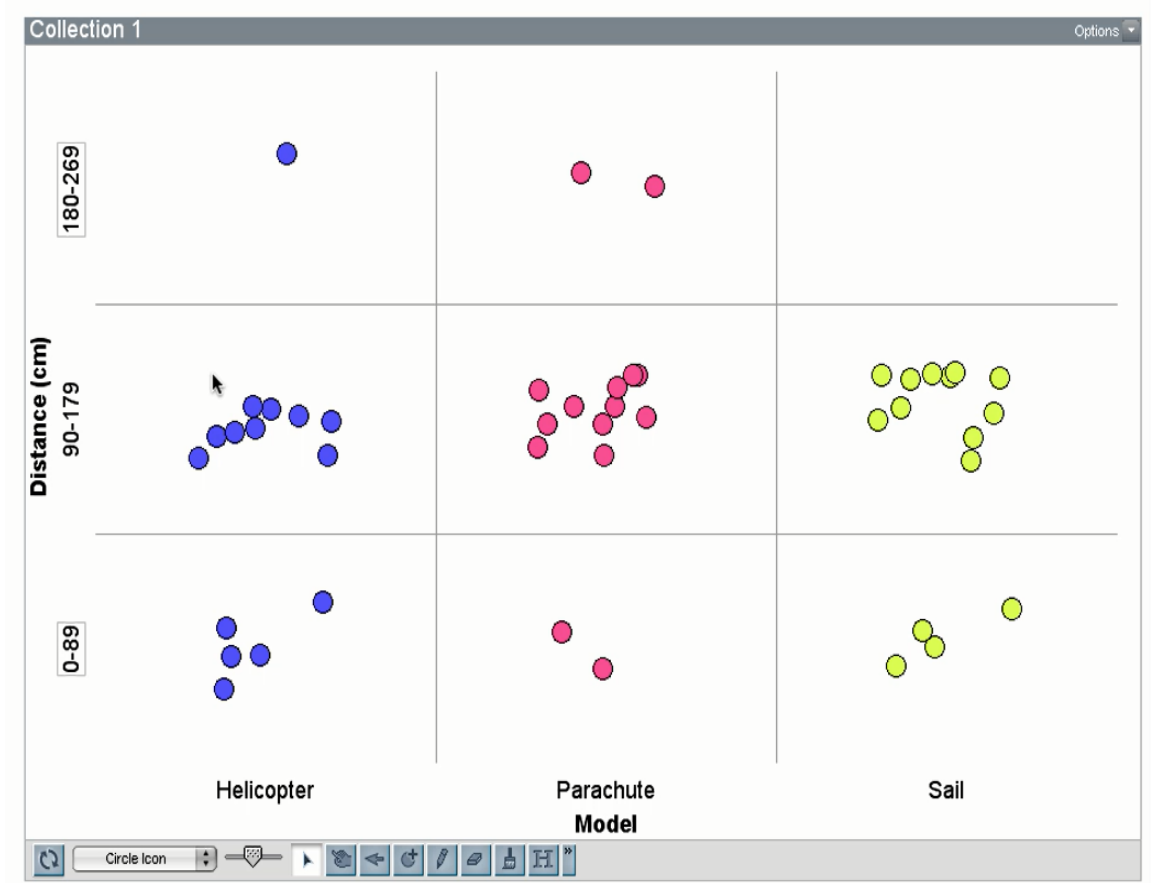

Figure 5c. Unstacked split dot plots showing Model and Distance, with data in bins $(\mathrm{n}=7)$ [e.g., ID149]

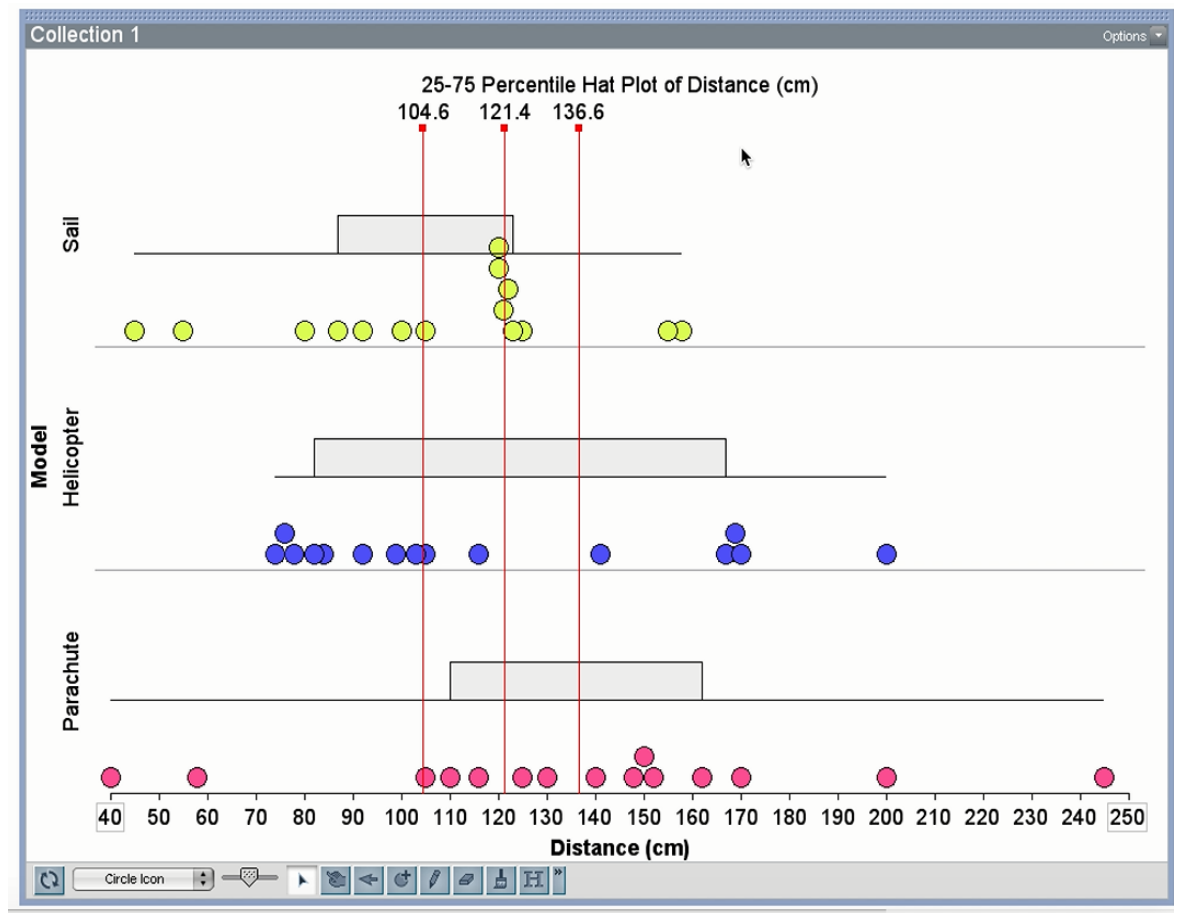

Figure 5d. 25-75 percentile hat plots of Distance (n=2) [e.g., ID161] 


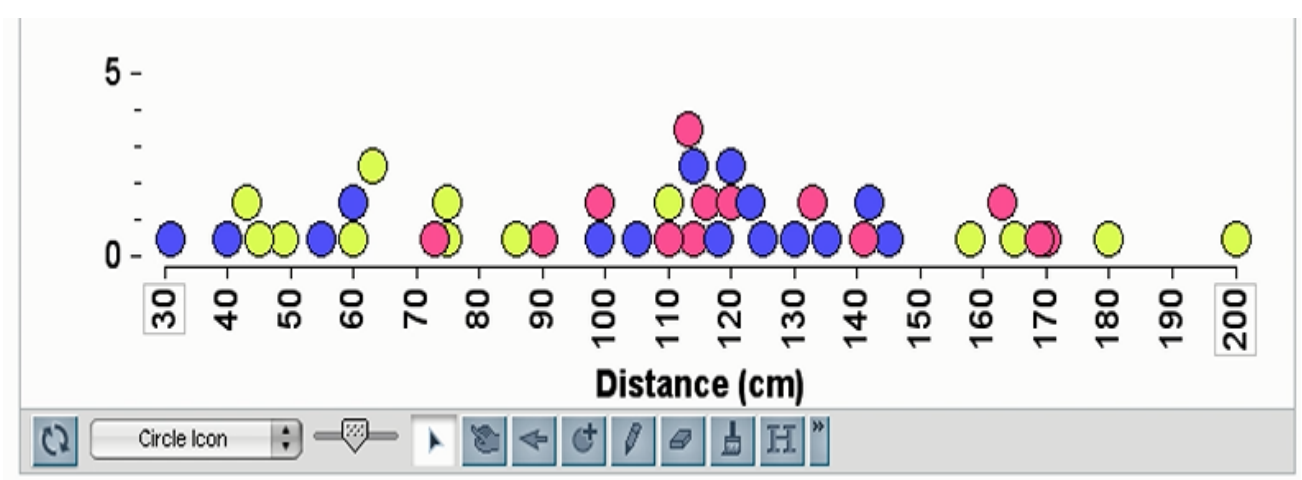

Figure 6a. Single variable plot coloured by Model (n=3) [e.g., ID154]

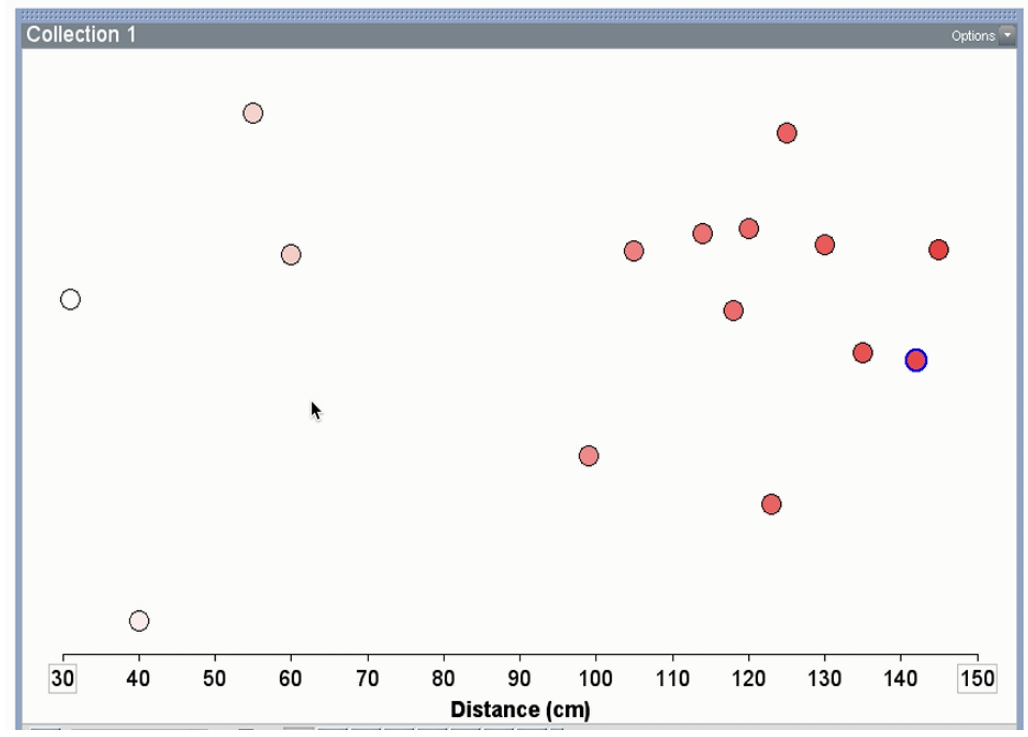

Figure 6b. Distance data for one Model only (n=1) [ID146]

Interview Responses

Across the 45 interviews, the students made a total of 1,029 comments that were coded for the four categories: (i) Reading the data (499 comments, 48\%); (ii) Reading within the data (400, 39\%); (iii) Reading behind the data (48 comments, 5\%), and (iv) Reading beyond the data ( 82 comments, $8 \%$ ). All 45 students made one or more data reading comment, and all demonstrated an ability to read within the data (range of 2 to 16 comments each). Twenty-four students (53\%) made up to six comments related to reading behind the data, and 27 students $(60 \%)$ read beyond the data, ranging from 1 to 11 comments each.

Reading the data: Recognising components of graphs. Almost half (48\%) of all coded comments related to reading the data and recognising graphical components. In response to direct questions, some students noted a single element; for example, when asked the distance travelled by a specific data case (e.g., 167 centimetres [ID153]), the model that travelled the shortest or longest distance (e.g., Umm, the helicopter [ID131]; So Group 3 had the furthest one [ID136]), or the Group number of a selected case (e.g., Group 1 [ID146]). Others identified multiple data reading elements for the one case (e.g., The bottom one is 40 centimetres for parachute [ID148]; It was a helicopter and it went 105 centimetres and the Group was 5 [ID155]). 
To assist in determining if one seed dispersal model went further than the others, some students read the legend (e.g., So the parachute is red. The blue one is a helicopter and the yellow one is sail. [ID158]). Others read the axes, as illustrated in the following exchange between the interviewer (I) and the student (S):

I: How did you know that is "helicopter"?

S: Because it says down the bottom [along the horizontal axis]. [ID162]

Reading within the data: Understanding relationships among elements of graphs and the data. All 45 students interviewed were able to read within the data to compare the performance of the three seed dispersal models. Examples include students using the data to decide which model went the furthest (e.g., Sail came first, then parachute second and helicopter third [ID106]), or where most of the data were situated (e.g., In the middle [ID159]). The students also responded to questions on consistency and variation, using the data to inform their decision. For example:

Maybe the sail [had the least consistency] because there's some down here, like the 60's and 70's, and there's some up here, but ... there's a big gap there. [ID129]

I think sail [has more variation]. Because, like, if you have a look at the helicopter that is still pretty far apart, but sail is more far apart. [ID139]

For some students, their comments illustrate the difficulty of reading within the data to make decisions. For example [ID110]:

I: So, does that help you maybe decide which one you think was the best method?

S: Probably the best method was parachute. They were all good methods, but parachute went the furthest, but at the same time it went the least furthest.

[A few minutes later.]

I: So now what would make you decide that one of those was better? What do you think?

$\mathrm{S}$ : Helicopter probably because it is like in the middle-ish and then sails like back that way and then parachute is all spread out.

Similarly,

So, the green one [sail] definitely is more consistently higher and parachute is just spread out and there's a lot of ones down here but at the same time most of the dots are further than the green. I think blue looks pretty good because there's so many up here. But I think red, parachute [is the best because of] the middle distance. [ID161]

Reading beyond the data: Interpreting information in the graph. Twenty-four students read beyond the data to interpret the information. Some used age-appropriate knowledge of seed dispersal and plant science to make decisions about the best method of dispersal. For example:

I would probably say the helicopters [are the best] because it travelled more consistent and it wasn't close, but it wasn't far away. With this one [parachute] it could land anywhere, it could land in a bad spot or it could land in a very good spot, but you would have no idea. But this one [helicopter] you know it is going to land probably in a good spot and this one [sail] is probably not the best because it doesn't go as far. [ID101]

[The parachute is best] because they spread out everywhere. And they're not bunched together in one spot where they can grow and this one they can grow further and spread out. [ID123]

Some students used the data to inform their decision on which model to make in the future. For example, ID127 would have chosen to make a parachute "because from the data most of the parachutes go further than the rest." Similarly, ID119 commented that she would "probably choose 
parachute because it also goes, like, the furthest." Others focused on the consistency of the models (e.g., Maybe sail ... so I can get a bit more consistency, so it doesn't go all over the place or it doesn't go too high or too low because it is mostly consistent [ID149]), and some noted that the decision is dependent on whether the device was for the seed to travel as far as possible, or land consistently. For example:

Again, depending on whether I wanted it to be consistent or go further away. Maybe the yellow ones, the sail ones. But if you wanted it to be more consistent I would probably go with the parachute ones. [ID113]

Reading behind the data: Looking for possible causes and implications of variation in the data. Sixty percent of the students used their memory of the activity to justify decisions about the data. For example, to explain the variation observed, ID136 commented, "I think Group 7 has got a very small amount of variation because they were probably, like, just kind of dropping it [in front of the fan]". She went on to explain that "helicopter probably didn't go as far because it is really hard to get the spin just right." Other examples include:

So, these guys [sails] obviously maybe dropped it different to these groups [helicopters and parachutes]. Because these people [helicopters] may have dropped it kind of similar to each other and that's why they have got the same. These people [sails] obviously dropped it a bit more, you know, not like the same as each other. That's why they have got these distances. [ID155]

Maybe because the parachute copped the wind and threw it further. [ID149]

Some, like ID136 above, commented on the impact on variation of the design of the seed dispersal device:

It depends what kind of parachute it is. Like, they could have made, the lowest one could have made a really bad one and it has gone down [only a little way] and every [other] one has gone far. [ID109]

Well, I guess it depends how you make it. [ID135]

...only some of them are down the bottom [of the scale] because that's how they made it. [ID154]

... these ones here, they probably used some of the same materials as each other. That's why they are all [together] and they probably look a bit the same because they are all around here and they went the same distance, nearly. [ID111]

Their memory of the activity also helped some students to justify their decision about which method is best. For example,

...the reason I think Sail is the best is because you use paper for the sail and paper likes to fly around. [ID147]

Probably the parachute. The sail might have gone further because it was easier to throw but then the helicopter, like, [you] had to make it spin and move at the same time. [ID119]

When choosing which model to design in the future, some students focussed on the materials:

I think I have learnt that it depends how you make it. Like it depends what materials you do. Like polystyrene, it is pretty light, so it would float better. If you used some stones or something it could weight it down, so it wouldn't be as fast. I think you have to be pretty careful with what you do. Maybe you want to make it as light as possible, I think because it can float. Like a feather. Chuck it up and it takes a while to sink down to the ground. [ID155] 
I would probably choose the sail because the sail you can make sort of lightish. Where with the helicopter you sort of got to add bits and bobs to make it similar to what a normal helicopter seed would look like and the parachute to make it sort of like glide instead of just sink. [ID125]

And helicopters sometimes they didn't move because they're too heavy. [ID141]

Another student, ID126, showed an appreciation of fair test conditions by suggesting everyone make the same type of device to "see which design was best for this particular seed."

\section{Discussion and Conclusion}

The research reported in this paper addresses the concern expressed by Rosicka (2016) that few studies report "on evidence-based practical applications, programs or interventions that can be implemented in the primary classroom to address STEM learning" (p. 4). It provides evidence of outcomes from taking an integrated approach to STEM learning through a focus on students working through the engineering design process (Ward et al., 2016) in tandem with the practice of statistics (Watson et al., 2018) to construct, trial, and improve a seed dispersal device (adapted from Pike, 2017). The engineering design process served as a pedagogical framework for directing the STEM investigation and the practice of statistics put the focus on using data to evaluate the performance of the seed dispersal devices, which included the original and modified devices.

The students in this study worked through the four stages of the practice of statistics described by Watson and her colleagues (2018) whilst also enacting the engineering design process in the construction and evaluation of seed dispersal devices (Ward et al., 2016). They demonstrated their capacity to collect, represent, and analyse the data, and make decisions about changes to devices based on their analyses. This put the use of data and subsequent analyses in the forefront of student decision-making in the Test and Evaluate phase of the engineering design process. Using the four categories of the Shaughnessy (2007) graph understanding framework to guide the student interviews aimed to draw out the connections students had made among the STEM disciplines associated with the learning activity.

Analysis of the graphical representations constructed by the students to show the distance travelled by the modified seed dispersal devices when launched in front of a fan revealed that the students chose a variety of graph types to display the data. Importantly, $89 \%$ of the students chose a representation that allowed them to compare directly the performance of the three types of devices: sails, helicopters, and parachutes. The capacity to do this was facilitated by using the educational data analysis software, TinkerPlots (Konold \& Miller, 2015). Drawing a graph by hand to compare the performance of three different devices may have resulted in representations that did not exhibit the accuracy needed to make the comparison.

The other factor that supported such a large majority of students to be able to construct useful graphical representations was the sustained learning in graph construction and graph interpretation experienced as part of participating in the longitudinal study from which this report was taken (Fitzallen \& Watson, in press; Watson, Fitzallen, English et al., 2019). The benefits of sustained learning that takes a developmental approach is well-documented in the educational research literature. Unfortunately, sustained STEM education learning experiences are not common place in schools (Rosicka, 2016).

Analysis of the interview transcripts revealed that all the students were able to read directly the details from the graphical representations to make comments about the relationships displayed by the graphs. However, connections to the more complex ideas of identifying the relationships among the data and making informal inferences that included the uncertainty evident in the data (Makar \& Rubin, 2009) were made by fewer students. 
When the students were asked about making potential changes to devices in the future, they started to make connections about the performance of the seed dispersal devices to their knowledge and understanding of content from the STEM disciplines. The students expressed ideas about flight, which is a Science concept, when they used terms like glide, float, and spin. In most of these instances the students related the terms to the ability of the devices to move and travel. Connections were made to Technology concepts when the students described the properties of the materials used to construct the devices. Some students were able to identify that the materials would affect the ability of the devices to move and travel. References to the design of the devices and how the different properties of the designs affected the way in which they caught the wind when launched demonstrated connections to Engineering concepts related to the performance and behaviour of a designed solution (ACARA, 2019).

Although this study illustrates the potential connections made by the students to the Science, Technology, and Engineering disciplines when the focus was on analysing and interpreting data, it did not explore the extent to which students understood the ideas expressed. It demonstrates, however, the benefit of including elements in data investigations that require students to go beyond the data collected for making connections to other disciplines. It appeared that when the students were required to justify decisions or make predictions or recommendations from the data, they related their ideas to the situation within which the data were collected. This provided the opportunity for students to demonstrate the connections they had made among the STEM disciplines. This research also adds weight to Rao's (1975) assertion that an interdisciplinary approach to learning suits the teaching of statistics.

Taking advantage of the opportunities for learning in all the STEM disciplines when implementing activities like designing and trialling a wind dispersal device poses many challenges. The seed dispersal activity focused on the $\mathrm{M}$ and $\mathrm{E}$ of the STEM acronym. It did not focus on the potential learning outcomes for the $\mathrm{T}$ and the $\mathrm{S}$. Had it done so, it would have been possible to explore and extend student understanding of the additional concepts of flight and the properties of materials they identified in the interviews. This implies that outcomes for all the potential STEM outcomes need to be considered when planning integrated learning activities, whether they be for research or enactment in the classroom. Adopting this view would assist in making STEM learning more purposeful and less incidental than currently implied when research set within STEM contexts only report on outcomes for one of the disciplines. Planning approaches such as Understanding by Design (Wiggins \& McTighe, 2011) that identify desired learning outcomes before choosing the learning activities to implement may assist in developing holistic integrated learning activities. This is not to suggest all four disciplines need to be incorporated in every activity. Rather, it promotes the view that integration of learning comes from purposeful and meaningful use of the ideas and concepts associated with the context of the situation chosen (Fraser et al., 2019). An increased research focus on ways in which planning frameworks can support teachers' skills in implementing STEM integrated learning would be beneficial.

\section{Acknowledgement}

This study was funded by an Australian Research Council Project (DP150100120). The opinions expressed in this report are those of the authors and not the Council. Thanks to Ben Kelly for assistance with coding the data and Caroline Smith for supporting the classroom implementation and assisting with the interviews. 


\section{References}

Australian Curriculum, Assessment and Reporting Authority. (2019). The Australian Curriculum. Retrieved from https:// www.australiancurriculum.edu.au/f-10-curriculum/

Becker, K., \& Park, K. (2011). Effect of integrative approaches among science, technology, engineering and mathematics (STEM) subjects on students' learning: A preliminary meta-analysis. Journal of STEM Education: Innovations and Research, 12(5/6), 23-37.

Blackley, S., \& Howell, J. (2015). A STEM Narrative: 15 Years in the Making. Australian Journal of Teacher Education, 40(7), 102-112. http://dx.doi.org/10.14221/ajte.2015v40n7.8

Cobb, P., Confrey, J., diSessa, A., Lehrer, R., \& Schauble, L. (2003). Design experiments in educational research. Educational Researcher, 32(1), 9-13.

Creswell, J. W. (2014). Research design: Qualitative, quantitative, and mixed methods approaches. Thousand Oaks, CA: SAGE Publications.

Curcio, F. R. (2001). Developing data-graph comprehension in grades $K-8$ ( $2^{\text {nd }}$ ed.). Reston, VA: National Council of Teachers of Mathematics.

English, L. D., Hudson, P. B. \& Dawes, L. (2013). Engineering-based problem solving in the middle school: design and construction with simple machines. Journal of Pre-College Engineering Education Research, 3(2), 43-55.

English, L., Watson, J., \& Fitzallen, N. (2017). Fourth-graders' meta-questioning in statistical investigations. In A. Downton, S. Livy, \& J. Hall (Eds.), 40 years on: We are still learning! Proceedings of the 40th annual conference of the Mathematics Education Research Group of Australasia, Melbourne, July 2-6 (pp. 229-236). Sydney: MERGA.

Fitzallen, N. (2015). STEM education: What does mathematics have to offer? In M. Marshman (Eds.), Mathematics Education in the Margins. Proceedings of the 38th annual conference of the Mathematics Education Research Group of Australasia, Sunshine Coast, June 28-July 2 (pp. 237-244). Sydney: MERGA. Retrieved from http://www.merga. net.au/documents/RP2015-22.pdf

Fitzallen, N., \& Watson, J. (in press). Using the practice of statistics to design students' experiences in STEM. In B. Shelley, K. te Riele, \& N. Brown (Eds.), Harnessing the transformative power of education. Leiden, The Netherlands: Koninklijke Brill.

Fitzallen, N., Watson, J., \& Wright, S. (2017). The heat is on! Using a stylised graph to engender understanding. Australian Primary Mathematics Classroom, 22(2), 3-7.

Fitzallen, N., Watson, J., Wright, S., \& Duncan, B. (2018). Data representations in a STEM context: The performance of catapults. In M. A. Sorto \& K. Makar (Eds.), Looking back, looking forward (Proceedings of the 10th International Conference on the Teaching of Statistics, Kyoto, Japan, July 8-14, 2018). Voorburg, The Netherlands: International Statistical Institute. Available at: https://iase-web.org/icots/10/proceedings/pdfs/ICOTS10_4B2.pdf

Fitzallen, N., Wright, S., Watson, J., \& Duncan, B. (2016). Year 3 students' conceptions of heat transfer. In M. Baguley (Ed.), Proceedings of the Annual Conference of the Australian Association for Educational Research. Melbourne: AARE. Retrieved from http://www.aare.edu.au/data/2016_Conference/Full_papers/361_Noleine_Fitzallen.pdf

Fontana, A., \& Frey, J. (2003). The interview: From structured questions to negotiated text. In N. K. Denzin \& Y. S. Lincoln (Eds.), Collecting and interpreting qualitative materials (pp. 61-106). Thousand Oaks, CA: SAGE Publications.

Franklin, C., Kader, G., Mewborn, D., Moreno, J., Peck, R., Perry, M., \& Scheaffer, R. (2007). Guidelines for assessment and instruction in statistics education (GAISE) report: A pre-K-12 curriculum framework. Alexandria, VA: American Statistical Association. Retrieved from http://www.amstat.org/education/gaise/

Fraser, S., Earle, J., \& Fitzallen, N. (2019). What is in an acronym? Getting to the heart of STEM education. In T. Barkatsas, N. Carr, \& G. Cooper (Eds.), STEM Education: An emerging field of inquiry (pp. 9-30). Lieden, The Netherlands: Koninklijke Brill.

Honey, M., Pearson, G., \& Schweingruber, H. (2014). STEM integration in K-12 education: Status, prospects, and an agenda for research. doi:10.17226/18612

Johnson, R. B., \& Onwuegbuzie, A. J. (2004). Mixed methods research: A research paradigm whose time has come. Educational Researcher, 33(7), 14-26.

Kelley, T. R., \& Knowles, J. G. (2016). A conceptual framework for STEM education. International Journal of STEM Education, 3(11). doi: 10.1186/s40594-016-0046-Z

Konold, C., \& Miller, C. D. (2015). TinkerPlots: Dynamic data exploration [Computer software, Version 2.3]. Emeryville, CA: Key Curriculum Press.

Kvale, S. (1996). Interviews: An introduction to qualitative research interviewing. Thousand Oaks, CA: SAGE Publications.

Lave, J. \& Wenger, E. (1991). Situated learning: Legitimate peripheral participation. Cambridge, United Kingdom: Cambridge University Press.

Lowrie, T., Leonard, S., \& Fitzgerald, R. (2018). STEM Practices: A translational framework for large-scale STEM education design. Educational Design Research, 2(1), Article 14. 
Makar, K., \& Rubin, A. (2009). A framework for thinking about informal statistical inference. Statistics Education Research Journal, 8(1), 82-105.

Moore, T. J., Guzey, S. S., \& Brown, A. (2014). Greenhouse design to increase habitable land: An engineering unit. Science Scope, 37(7), 51-57.

Moore, D. S., \& McCabe, G. P. (1989). Introduction to the practice of statistics. New York: W. H. Freeman.

Moore, T. J., \& Smith, K. A. (2014). Advancing the state of the art of STEM integration. Journal of STEM Education: Innovations and Research,15(1), 5-10.

Pike, L. A. (2017). Using math to support claims about wind-dispersed seeds. Science Scope, 40(8), 68-74.

Rao, C. R. (1975). Teaching of statistics at the secondary level: An interdisciplinary approach. International Journal of Mathematical Education in Science and Technology, 6, 151-162.

Rosicka, C. (2016). From concept to classroom: Translating STEM education research into practice. Camberwell, Australia: Australian Council for Educational Research.

Shaughnessy, J. M. (2007). Research on statistics learning and reasoning. In F. K. Lester, Jr. (Ed.), Second handbook on research on mathematics teaching and learning (pp. 957-1009). Charlotte, NC: Information Age Publishing.

Shaughnessy, M. (2013). Mathematics in a STEM context. Mathematics Teaching in the Middle School, $18(6), 324$.

Silverman, D. (2003). Analyzing talk and text. In N. K. Denzin \& Y. S. Lincoln, Collecting and interpreting qualitative materials (pp. 340-362). Thousand Oaks, CA: SAGE Publications.

Smith, C., Fitzallen, N., Watson, J., \& Wright, S. (2019). The practice of statistics for STEM: Primary students and preservice primary teachers exploring variation in seed dispersal. Teaching Science, 65(1), 38-47.

Vasquez, J. (2015). STEM: Beyond the acronym. Educational Leadership, 72(4), 10-15.

Ward, L., Lyden, S., \& Fitzallen, N. (2016). Egg-streme egg crashes. Australian Mathematics Teacher, 70(2), 10-15.

Watson, J., Fitzallen, N., Fielding-Wells, J. \& Madden, S. (2018). The practice of statistics. In D. Ben Zvi, J. Garfield, \& K. Makar (Eds.), International Handbook of Research in Statistics Education (pp. 105-137). Cham, Switzerland: Springer.

Watson, J., Fitzallen, N., English, L., \& Wright, S. (2019). Introducing statistical variation in year 3 in a STEM context: Manufacturing licorice. International Journal of Mathematical Education in Science and Technology. [Online] doi: 10.1080/0020739X.2018.1562117.

Watson, J., Fitzallen, N., \& Wright, S. (2019). Practicing statistics in Year 4. In C. Hurst et al. (Eds.), Mathematics Education Research: Impacting Practice. Proceedings of the 42nd annual conference of the Mathematics Education Research Group of Australasia, Perth, June 30- July 4. Sydney: MERGA.

Wiggins, G. P., \& McTighe, J. (2011). The understanding by design guide to creating high-quality units. Alexandria, VA: ASCD. 